\title{
Patients' attitudes toward the use of IoT medical devices: empirical evidence from Romania
}

\author{
Iustina-Cristina COSTEA-MARCU \\ Politehnica University, Bucharest, Romania \\ costeamarcuiustina@gmail.com \\ Gheorghe MILITARU \\ Politehnica University, Bucharest, Romania \\ ghmilitaru.militaru@gmail.com
}

\begin{abstract}
The Internet of Things (IoT) in healthcare sector is the collection of medical devices and applications that connect through online computer networks. The purpose of this study is to analyse the acceptance of medical devices that are based on IoT technology and monitor the health of individuals/patients. Most IoT medical initiatives have been focused on remote monitoring, improving patient care through various sensors and data processing those measures, for example, patients' vital signs. In medical services trust plays a key role in the patients' decision to adopt IoT technologies in medical industry. For this analysis, the Technology Acceptance Model was adopted in order to explain the way users accept and utilize these new medical devices that are based on IoT technology. The model was also used in order to identify those factors that influence the patients' decision of accepting this technology and also analyse the way they use it. Cross-sectional data were collected from 96 patients through a survey. Data were then analysed by means of multiple regression analysis. The findings verified the research hypotheses. Thus, different securities challenges could face the adoption of the IoT. In addition, privacy requirements are another major challenge in using these technologies. Risks arise where devices and applications are untested, resulting in issues with interoperability, stability, compatibility and data security. For the elderly and people with disabilities, these IoT provisions are very useful in providing autonomy, a personalized approach and permanent monitoring. The theoretical contributions and practical implications of the study are discusses.
\end{abstract}

Keywords: Internet of Things, adoption, information security, healthcare, medical devices.

\section{Introduction}

The medical industry is developing alongside technological progress by adopting the most recent IT technologies. The use of Internet of Things (IoT) technology in medicine can be seen in various cases: taking care of patients through autonomy insurance, the day to day monitoring of health, making effective use of medical services in a clinic, the autonomous collections and processing of data, etc.

The purpose of this study is to analyze the acceptance of medical devices that are based on IoT technology and monitor the health of individuals by utilizing the Technology Acceptance Model. The current study has been carried out to observe the patients attitude regarding the use of medical devices which can be easily accessible for daily use. The consumers' interest in collecting personal data has been influenced due to the wide variety of devices with reduced prices which are destined for monitoring and offering a healthy lifestyle.

Lately, engineering and medicine have had a very tight connection. For the new medical equipment there have been installed mobile communication devices, RFID tags, 
action devices, specialized sensors. This type of equipment allows reduced costs regarding medical services and better monitoring, customization and assistance for the patient. The Internet of Things (IoT), including carry-on devices, smartphone applications and home monitoring equipment, bring potentially valuable data in the clinic environment.

IoT aims to integrate and unify all the systems and communications that surround us. Thus, these systems can obtain total control and access over all the other systems, leading to the input of homogenous communications and calculations in order to define a new generation of assistance services (Velera,A. , Zamora, M., \& Skarmeta, A., 2010).

The article commences with an academic literature study and with the hypotheses which will be assessed further on. Thereafter, the methodology is presented and the obtained results are analyzed and interpreted. At the end of the paper, the hypotheses are validated and a conclusion is drawn.

\section{Literature review and hypotheses The Internet of Things}

The Internet of Things can be defined as interconnected devices which interact through the internet in order to allow the collection and exchange of data (Dimitrov, 2016).

Architecturally, the Internet of Things is structured on 3 layers: the perceptual layer formed from sensors (e.g., impulse sensors which allow cardiac arrest detection and pulmonary diseases, respiratory rate sensors which help identify asthma and apnea, body temperature sensors which can help to identify hypothermia), the internet and mobile communications network and the application referring to the operations and intelligent data processing ( Lu \& Liu, 2011).

In the medical domain the most important advantages that IoT provides are: reducing the time and costs of patient transport, the distribution of medical services in hardly accessible areas, the improvement of medical information supply for the medical personnel from distant areas (Islam et al., 2015). Intelligent medical equipment will help transmit professional consultations in the shortest time possible in order to delay the disease triggering and it taking effect (Wang, Yu \& Li, 2011).

There are three important technological tendencies which help developing medical assistance through IoT devices: biological data collection through biosensors, diagnosing the point of care (POC), developing medical applications based on IoT (Sheikh N.J. \& Sheikh O., 2016).

The biosensors make use of a biological molecule's property in order to convert a biologic signal into an optoelectronic, piezoelectric or electrochemical signal. Devices that measure multiple factors at the same time can be developed with the aid of a multi-sensor. The technology of body sensor networks (BSN) is one of the main technologies of integrating IoT into the healthcare system. This represents a collection of sensor nodes without lowpower and lightweight which are used for monitoring human body activities and the environment (Gope \& Hwang, 2016). POC devices are based on molecular diagnosis, disease identification and providing treatment.

\section{Applications of IoT technologies into the medical domain}

Population ageing and the increasing of the disease rate raise the demand for the following resources: hospital beds, rooms, nurses, medics. Because of this, remotely monitoring the 
patients' health is the first step into solving the limited medical resources problem (Baker, Xiang \& Atkinson, 2017). Thanks to technological development the traditional medical methods do not suffice the individual health needs any longer.

At the moment there are plenty researches involving IoT technology in the medical domain. There have been carried out case studies starting from the proposal of some informational systems based on the useful IoT technology in order to analyze data. For example, Antonio Jara proposed an informational pharmaceutical system which helps detect some negative drug reactions (Jara et al., 2010). At the same time, there are different approaches towards decision support systems and home monitoring systems, for example for patients with neurological problems (Chiuchisan \& Geman, 2014), patients with diabetes (Chang S, Chiang S. \& Chang W., 2016) or those with Parkinson (Pasluosta et al., 2015).

Hu F., Xie D., Shen S. (2013) propose a new concept, focusing on how to apply IoT into medical healthcare, medical equipment, drugs control, medical information management, telemedicine and mobile medical assistance.

Healtcare industry is making increasing changes due to the introduction of the latest technology. In health processes tracking devices along with wearables are a daily part of dayto-day health monitoring processes. Data stored to determine aspects of people's lifestyle, treatment plans, surgical plans, dietary monitoring, heart rate, etc., need to be analyzed to get an appropriate medical approach. $87 \%$ of healthcare organizations around the world intend to deploy IoT services by 2019, making IoMT (Internet of Medical Things) one of the most sought-after technology platforms in the coming years. (Alsubaei F., 2018)

Currently, the IoT solutions offered by various organizations are registered in the following categories: Hospital / clinical efficiency, monitoring home consumers, fitness monitor, baby monitor, neurotechnology, sleep monitors. Following patient consultations in clinics, treatments can be monitored and some statistics can be made. At the same time, track of medical equipment can be kept in order to see their availability. Hospitals and clinics need a solution that provides real-time overall visibility of: the location of patients and their status, the location of the staff and the activity they are employed in, the location of the equipment and its availability. A solution that provides visibility for rooms and patient status would also be useful. This gives an overview of the patient's location and provides information about the status of the room: available, in use, reserved, in the cleaning process, requires cleaning. Alerts can be generated (e.g. on smartphones). For example, when entering the clinic the patient is assigned with a small WiFi bangle and will be watched until he leaves the clinic. Key assets such as wheelchairs, infusion pumps, stretchers, and inhalators are equipped with WiFi sensors and also during their shift staff members wear a badge with sensors. This makes it easier to automatically track the location of human and material resources. Of course, based on the gathered data, analyzes can be made to measure performance and improve processes. At the consumer's home, IoT technology is directly acquired for self-monitoring and information gathering at their dwelling. For example, a smart thermometer that makes use of the temperature sensors in smartphones or other devices. For diabetics, the blood glucose is delivered in real time and alerts are sent so that the patient or medical staff intervenes when needed. Nowadays, there are devices on the market that can get an electrocardiogram at home. Fitness monitors can adapt a certain fitness regime to an individual after collecting data. Currently, these devices that are connected to smart phone applications are very popular. Brain sensors are IoT medical devices that are capable of reading brain waves and 
can be used for example to analyze the effects of drug use. For those suffering from degenerative diseases, the patient's movement and balance are monitored, and when the sensors detect that the individual has fallen, patient caregivers are alerted. Infant Monitoring allows monitoring and storage of data related to sleep pattern, temperature, sounds, etc. The parents are constantly informed about the condition of their child by receiving information on the phone / smartwatch. For sleep disturbances or neuropsychological disorders, sleep monitoring is useful to treat these disorders. Devices based on IoT technology can transmit information to doctors in other locations.

\section{The TAM Model}

There are two measurable variables proposed by the TAM model for the consumer's intention to put technology to good use. One is perceived usefulness (PU) and the other is the perceived ease-of-use (PEOU)(Davis et al., 1989). The first mentioned variable is defined as the consumer's perception on how the technology will improve his/her lifestyle, while the second variable is demonstrating the consumer's perception on the effort necessary to use the system.

Hypotheses.

IoT medical technologies should reach better adoption rates in order to facilitate the life of the users. The acceptance of medical devices based on IoT technology will be further analyzed, taking into consideration certain factors. Hence, the following hypotheses are listed:

H1: Perceived usefulness positively affects a consumer's intention to use medical devices based on IoT technologies.

H2: Perceived ease of use positively affects a consumer's intention to use medical devices based on IoT technologies.

H3: Social influence positively affects a consumer's intention to use medical devices based on IoT technologies.

H4: Perceived confidence positively affects a consumer's intention to use medical devices based on IoT technologies.

\section{Methodology}

A survey questionnaire was applied to a sample of 96 people aged 20-50 who have basic knowledge of medical devices that use IoT technology. There are 20 questions listed in the survey and all of them were presented as 5 point Likert Scale (ranging from $1=$ strongly disagree to $5=$ strongly agree). The questions of this survey have been integrated with the factors of perceived usefulness (PU), perceived ease of use (PEOU), social influence (SI), perceived confidence (PI) and behavioral intention to use (BI).

For this analysis, the Technology Acceptance Model was adopted in order to explain the way users accept and utilize these new medical devices that are based on IoT technology. The model was also used in order to identify those factors that influence the patients' decision of accepting this technology.

For this data analysis IBM SPSS Statistics software package version 22 was used and IBM SPSS Amos software package version 25. 


\section{Results and discussions}

Two tests are presented in the table below (Table 1) to indicate the suitability of the collected data. In this study, Kaiser-Meyer-Olkin Measure of Sampling Adequacy indicates a value above 0.5 , close to 1.0. This indicates that the factor analysis will be useful with the dates. The Bartlett's Test of Sphericity shows a value less than 0.05 witches indicate that a factor analysis will be useful with the data.

Table 1. KMO and Bartlett's Test

\begin{tabular}{|c|c|c|}
\hline \multicolumn{2}{|c|}{ Kaiser-Meyer-Olkin Measure of Sampling Adequacy. } & .768 \\
\hline \multirow[t]{3}{*}{ Bartlett's Test of Sphericity } & Approx. Chi-Square & 2657.037 \\
\hline & $\mathrm{df}$ & 190 \\
\hline & Sig. & .000 \\
\hline
\end{tabular}

Source: Authors' own research.

Factors indicating the intention to use medical devices based on IoT technology are highlighted in Table 2. The following are also indicated: the rotated factor loadings, the mean and the standard deviation. It can be seen that the BI factor has the closest average to the central value, which confirms that PU, PEOU, SI, PC are the factors that are at the foundation of using the medical devices based on IoT devices.

Table 2. Factor Loadings and Descriptive Statistics

\begin{tabular}{|c|c|c|c|c|c|c|c|}
\hline \multicolumn{6}{|c|}{ Rotated Component Matrix ${ }^{a}$} & \multirow[t]{3}{*}{ Mean } & \multirow[t]{3}{*}{$\begin{array}{c}\text { Std. } \\
\text { Deviation }\end{array}$} \\
\hline & \multicolumn{5}{|c|}{ Factor Loadings } & & \\
\hline & 1-PU & 2 -PEOU & 3 -SI & $4-\mathrm{PC}$ & 5 - BI & & \\
\hline \multicolumn{6}{|c|}{ Perceived Usefulness (PU) } & 3.9531 & 1.02874 \\
\hline Q1 & .788 & & & & & & \\
\hline $\mathrm{Q} 2$ & .884 & & & & & & \\
\hline Q3 & .696 & & & & & & \\
\hline $\mathrm{Q} 4$ & .882 & & & & & & \\
\hline \multicolumn{6}{|c|}{ Perceived Ease of Use (PEOU) } & 4.2743 & .57225 \\
\hline Q5 & & .737 & & & & & \\
\hline Q6 & & .895 & & & & & \\
\hline Q7 & & 463 & & & & & \\
\hline \multicolumn{6}{|c|}{ Social Influence (SI) } & 3.1493 & .92511 \\
\hline Q8 & & & .871 & & & & \\
\hline Q9 & & & .700 & & & & \\
\hline Q10 & & & .829 & & & & \\
\hline \multicolumn{6}{|c|}{ Perceived Confidence (PC) } & 3.9167 & .63090 \\
\hline Q11 & & & & .564 & & & \\
\hline Q12 & & & & .917 & & & \\
\hline Q13 & & & & .900 & & & \\
\hline Q14 & & & & .847 & & & \\
\hline Q15 & & & & .838 & & & \\
\hline \multicolumn{6}{|c|}{ Behavioral Intention (BI) } & 3.5333 & .78387 \\
\hline Q16 & & & & & .535 & & \\
\hline Q17 & & & & & .745 & & \\
\hline Q18 & & & & & .948 & & \\
\hline Q19 & & & & & .484 & & \\
\hline
\end{tabular}




\begin{tabular}{|c|c|c|c|c|c|c|c|}
\hline \multicolumn{6}{|c|}{ Rotated Component Matrix ${ }^{a}$} & \multirow[t]{3}{*}{ Mean } & \multirow[t]{2}{*}{$\begin{array}{c}\text { Std. } \\
\text { Deviation } \\
\end{array}$} \\
\hline & \multicolumn{5}{|c|}{ Factor Loadings } & & \\
\hline & 1-PU & 2 -PEOU & 3 - SI & $4-\mathrm{PC}$ & 5 - BI & & \\
\hline Q20 & & & & & .667 & & \\
\hline \multicolumn{8}{|c|}{$\begin{array}{l}\text { Extraction Method: Principal Component Analysis. } \\
\text { Rotation Method: Varimax with Kaiser Normalization. }\end{array}$} \\
\hline
\end{tabular}

PICBE | 572

Source: Authors' own research.

In Table 3 the Cronbach`s Alpha coefficient is presented in order to analyze the internal consistency of the questionnaire's factors. The minimum value for alfa is 0.6 (Hair et al., 1998), and in the given case the majority hold a greater value.

Table 3. Descriptive Statistics

\begin{tabular}{|c|c|c|}
\hline No crt & Factor & Cronbach s Alpha \\
\hline 1 & Perceived Usefulness (PU) & 0.931 \\
\hline 2 & Perceived Ease of Use (PEOU) & 0.538 \\
\hline 3 & Social Influence (SI) & 0.857 \\
\hline 4 & Perceived Confidence (PC) & 0.689 \\
\hline 5 & Behavioral Intention (BI) & 0.777 \\
\hline
\end{tabular}

Source: Authors' own research.

It can be seen that the best consistence of Cronbach`s Alpha coefficient is the PU factor and together with PEOU, SI, PC they are significant factors that form the basis of the intention to use medical devices based on IoT technology.

Table 4 shows the inter-correlation analysis. It can be seen that all the analyzed factors have correlated with significant values. The value of the inter-correlations between the 5 factors has varied from 0.2 to 0.674

Table 4. Correlations analysis

\begin{tabular}{|ll|r|r|r|r|r|}
\hline & \multicolumn{1}{|c|}{ PU } & \multicolumn{1}{c|}{ PEOU } & \multicolumn{1}{c|}{ SI } & \multicolumn{1}{c|}{ PC } & \multicolumn{1}{c|}{ BI } \\
\hline PU & Pearson Correlation & 1 & $.658^{* *}$ & $.399^{* *}$ & $.515^{* *}$ & $.516^{* *}$ \\
& Sig. (2-tailed) & & .000 & .000 & .000 & .000 \\
& $\mathrm{~N}$ & 96 & 96 & 96 & 96 & 96 \\
\hline PEOU & Pearson Correlation & $.658^{* *}$ & 1 & .200 & $.653^{* *}$ & $.514^{* *}$ \\
& Sig. (2-tailed) & .000 & & .051 & .000 & .000 \\
& $\mathrm{~N}$ & 96 & 96 & 96 & 96 & 96 \\
\hline SI & Pearson Correlation & $.399^{* *}$ & .200 & 1 & $.212^{*}$ & $.570^{* *}$ \\
& Sig. (2-tailed) & .000 & .051 & & .039 & .000 \\
& $\mathrm{~N}$ & 96 & 96 & 96 & 96 & 96 \\
\hline PC & Pearson Correlation & $.515^{* *}$ & $.653^{* *}$ & $.212^{*}$ & 1 & $.674^{* *}$ \\
& Sig. (2-tailed) & .000 & .000 & .039 & & .000 \\
& $\mathrm{~N}$ & 96 & 96 & 96 & 96 & 96 \\
\hline BI & Pearson Correlation & $.516^{* *}$ & $.514^{* *}$ & $.570^{* *}$ & $.674^{* *}$ & 1 \\
& Sig. (2-tailed) & .000 & .000 & .000 & .000 & \\
& $\mathrm{~N}$ & 96 & 96 & 96 & 96 & 96 \\
\hline
\end{tabular}

**. Correlation is significant at the 0.01 level (2-tailed).

*. Correlation is significant at the 0.05 level (2-tailed).

Source: Authors' own research. 
Next, the regression has been calculated according to Table 5. The goal of the multiple regressions is to highlight the relation between the dependent variable (BI) and the set of independent variables (PU, PEOU, SI, PC). The adjusted $\mathrm{R}^{2}$ value indicates that $65 \%$ of the BI variation is represented by the PU, PEOU, SI, PC.

The value of the threshold for $\mathrm{F}$ (the probability to go wrong when the null hypothesis is eliminated) is 0 . So, the null hypothesis can be negated and the research hypothesis can be accepted.

Table 5. Regression analysis

Model Summaryb

\begin{tabular}{|c|c|c|c|c|c|c|c|c|c|c|}
\hline \multirow[b]{2}{*}{ Model } & \multirow[b]{2}{*}{$\mathrm{R}$} & \multirow[b]{2}{*}{$\begin{array}{c}\mathrm{R} \\
\text { Square } \\
\end{array}$} & \multirow[b]{2}{*}{$\begin{array}{c}\text { Adjuste } \\
\text { d R } \\
\text { Square }\end{array}$} & \multirow[b]{2}{*}{$\begin{array}{l}\text { Std. Error } \\
\text { of the } \\
\text { Estimate }\end{array}$} & \multicolumn{5}{|c|}{ Change Statistics } & \multirow[b]{2}{*}{$\begin{array}{l}\text { Durbin- } \\
\text { Watson }\end{array}$} \\
\hline & & & & & $\begin{array}{l}\text { R Square } \\
\text { Change }\end{array}$ & F Change & df1 & $\mathrm{df} 2$ & $\begin{array}{c}\text { Sig. F } \\
\text { Change }\end{array}$ & \\
\hline 1 & $.806^{a}$ & .650 & .635 & .47389 & .650 & 42.234 & 4 & 91 & .000 & 2.263 \\
\hline
\end{tabular}

a. Predictors: (Constant), PU, PEOU, SI, PC

b. Dependent Variable: BI

Source: Authors' own research.

In Figure 1 the regression graphic is presented, having BI (Behavioral Intention) as the dependent variable. It can be seen that in the inferior part of the graph the dots are above the line (showing that foe small values the regression model has a tendency to over evaluate the reality), and in the superior part the opposite can be seen (for greater values the tendency to under estimate the reality appears).

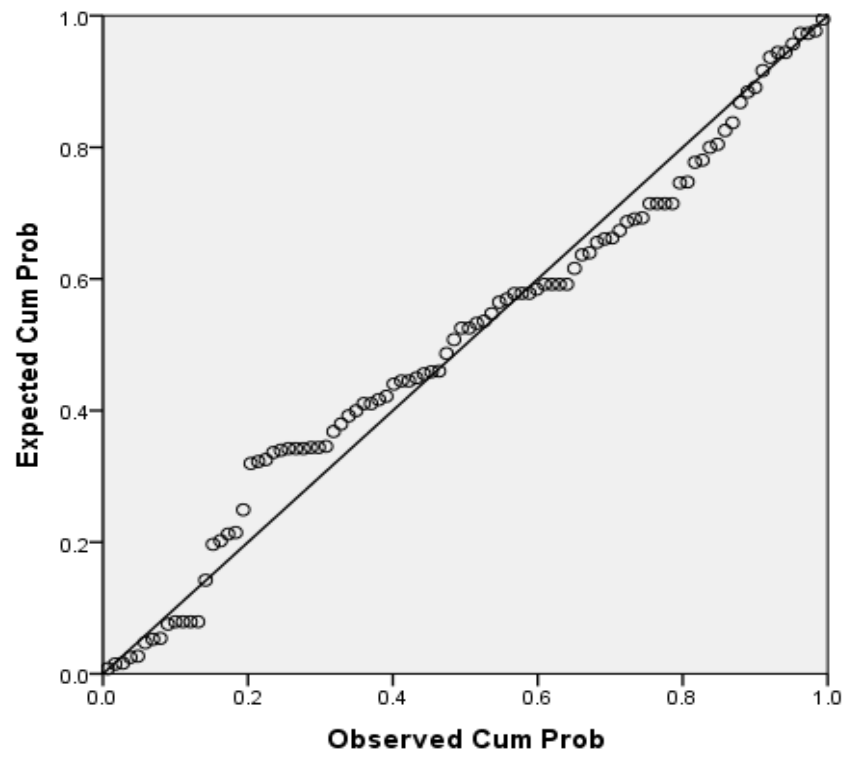

Figure 1. Normal P-P Plot Regression Standardized Residual

Source: Authors' own research.

Table 6 reports how well the regression equation fits the data and it is shown below. It indicates the fact that the regression model predicts the dependent variable significantly 
well. The statistical significance of the regression model is less than 0.05 and indicates the regression model statistically significantly predicts the outcome variable.

Table 6. ANOVAa

\begin{tabular}{|ll|r|r|r|r|r|}
\hline Model & Sum of Squares & \multicolumn{1}{c|}{ df } & Mean Square & \multicolumn{1}{c|}{ F } & \multicolumn{1}{c|}{ Sig. } \\
\hline 1 & Regression & 37.938 & 4 & 9.484 & 42.234 & $.000^{\mathrm{b}}$ \\
& Residual & 20.436 & 91 & .225 & & \\
& Total & 58.373 & 95 & & & \\
\hline
\end{tabular}

a. Dependent Variable: BI

b. Predictors: (Constant), PU, PEOU, SI, PC

Source: Authors' own research.

Table 7 lists the result obtained from multiple regression test. It can be observed the power of each prediction variable that suggests the dominance of the largest. For Social Influence has the highest value $t=6.389$ with a significance less than $0.05(\mathrm{p}<0.05)$.

Table 7. Regression analysis on the behavioral intention to use medical devices based on IoT technology in Romania; Coefficients a

\begin{tabular}{|c|c|c|c|c|c|c|c|c|}
\hline & \multirow[b]{2}{*}{ Model } & \multicolumn{2}{|c|}{$\begin{array}{c}\text { Unstandardized } \\
\text { Coefficients } \\
\end{array}$} & \multirow{2}{*}{$\begin{array}{c}\text { Standardized } \\
\text { Coefficients }\end{array}$} & \multirow[b]{2}{*}{ t } & \multirow[b]{2}{*}{ Sig. } & \multicolumn{2}{|c|}{ Collinearity Statistics } \\
\hline & & B & Std. Error & & & & Tolerance & VIF \\
\hline \multirow[t]{5}{*}{1} & (Constant) & -.648 & .404 & & -1.602 & .113 & & \\
\hline & PU & .022 & .068 & .029 & .324 & .747 & .485 & 2.061 \\
\hline & PEOU & .089 & .130 & .065 & .685 & .495 & .428 & 2.339 \\
\hline & SI & .368 & .058 & .435 & 6.389 & .000 & .831 & 1.204 \\
\hline & PC & .652 & .103 & .525 & 6.324 & .000 & .559 & 1.790 \\
\hline
\end{tabular}

a. Dependent Variable: BI

Source: Authors' own research

Table 8 shows the Standardized Regression Weights. This table is generated in AMOS software and the data is useful for the TAM model.

Table 8. Standardized Regression Weights

\begin{tabular}{|ll|r|}
\hline & & Estimate \\
\hline IC $<---$ & PU & .029 \\
IC $<---$ & PEOU & .068 \\
IC <--- & SI & .455 \\
IC <--- & PC & .536 \\
\hline
\end{tabular}

Source: Authors' own research

In Figure 2 the values from Table 8 are presented in order to validate the hypothesis. The Social Influence and Perceived Confidence had a strong positive effect on consumer' behavioral intention to use medical devices based on IoT technology with the significant level $\mathrm{p}<0.001$. 


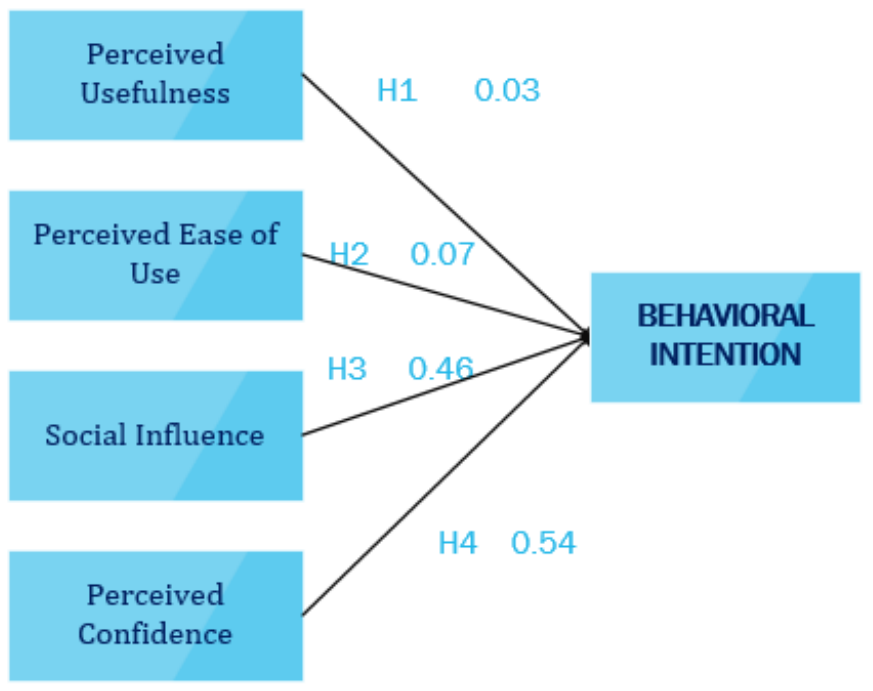

PICBE | 575

\section{Figure 2. Research Model Regarding Behavioral Intention to use medical devices based on IoT technology in Romania}

Source: Authors' own research.

The Technology Acceptance Model has been validated because people consider perceived medical devices that are based on IoT technology to be useful and also feel that given the high level of familiarity with everyday devices, those devices are also perceived to be easy to use.

Table 9 verifies whether the hypotheses have been validated or not.

Table 9. Verifying the hypotheses

\begin{tabular}{|c|c|c|c|c|}
\hline $\begin{array}{c}\text { Number of } \\
\text { hypothesis }\end{array}$ & Hypothesis & Coefficient $\boldsymbol{\beta}$ & Error & Validation \\
\hline $\mathrm{H} 1$ & $\begin{array}{c}\text { Perceived Usefulness positively affects a } \\
\text { consumer`s intention to use medical devices } \\
\text { based on IoT technologies. }\end{array}$ & 0.022 & 0.064 & Validate \\
\hline $\mathrm{H} 2$ & $\begin{array}{c}\text { Perceived Ease of Use positively affects a } \\
\text { consumer`s intention to use medical devices } \\
\text { based on IoT technologies. }\end{array}$ & 0.089 & 0.113 & Validate \\
\hline $\mathrm{H} 3$ & $\begin{array}{c}\text { Social Influence positively affects a consumer`s } \\
\text { intention to use medical devices based on IoT } \\
\text { technologies. }\end{array}$ & 0.368 & 0.054 & Validate \\
\hline $\mathrm{H} 4$ & $\begin{array}{c}\text { Perceived Confidence positively affects a } \\
\text { consumer`s intention to use medical devices } \\
\text { based on IoT technologies. }\end{array}$ & 0.652 & 0.079 & Validate \\
\hline
\end{tabular}

Source: Authors' own research.

The results confirm other studies that refer to the acceptance of IoT technology using Technology Acceptance Model. Wang, Yan, Hu and Zang (2011) were developed the TAM research by integrating six constructions: Perceived Structure Assurance, Perceived Privacy, Perceived Security Protection, Perceived Usefulness, Perceived Ease of Use, Consumer 
Disposition to Trust and Intension to Use. All the hypotheses say that each variable will influence the intention to use and apart from the first hypothesis ("A consumer's perceived structural assurance positively affects a consumer's intension to use IOT technologies."), all hypotheses are accepted.

\section{Conclusion}

This study indicates an analysis regarding the acceptance of Romanian consumers of medical devices based on IoT devices. Following the executed analysis, it has been remarked that the intention to utilize medical devices based on IoT technology is influenced by four factors: Perceived Usefulness, Perceived Ease of Use, Social Influence and Perceived Confidence.

The study has been limited to analyzing the medical devices based on IoT technology that can be easily accessible and used by anyone. Also, the study has been focused on a population that holds basic knowledge regarding the applications of IoT technologies into the medical domain.

For future references, the analysis of the acceptance of medical equipment with IoT technology in hospitals, institutions and dwellings is desired.

The results obtained were also confirmed in the Shin and Hwang research (2017), where is show the interaction between the social and technical factors of medical devices based on IoT technology (the interface of device and interaction).

\section{References}

Alsubaei, F., Abuhussein, A., \& Shiva, S. (2018, November). A Framework for Ranking IoMT Solutions Based on Measuring Security and Privacy. In Proceedings of the Future Technologies Conference (pp. 205-224). Springer, Cham.

Baker, S. B., Xiang, W., \& Atkinson, I. (2017). Internet of Things for Smart Healthcare: Technologies, Challenges, and Opportunities. IEEE Access, 5, 26521-26544.

Chang, S. H., Chiang, R. D., Wu, S. J., \& Chang, W. T. (2016). A context-aware, interactive Mhealth system for diabetics. IT Professional, (3), 14-22. S. H. Chang, R. D. Chiang, S. J. $\mathrm{Wu}$, and W. T. Chang, "A Context-Aware, Interactive M-Health System for Diabetics," IT Professional, vol. 18, no. 3, pp. 14-22, 2016

Chiuchisan, I., Geman, O. (2014). An approach of a decision support and home monitoring system for patients with neurological disorders using internet of things concepts. WSEAS Transactions on Systems, 13(1), 460-469.

Davis, Fred \& Bagozzi, Richard \& R. Warshaw, Paul. (1989). User Acceptance of Computer Technology: A Comparison of Two Theoretical Models. Management Science. 35. 982-1003. 10.1287/mnsc.35.8.982.

Dimitrov, D. V. (2016). Medical internet of things and big data in healthcare. Healthcare informatics research, 22(3), 156-163.

Gope, P., \& Hwang, T. (2016). BSN-Care: A secure IoT-based modern healthcare system using body sensor network. IEEE Sensors Journal, 16(5), 1368-1376.

Hair, J.F., Anderson, R.E., Tatham, R.L., \& Black, W.C. (1998). Multivariate data analysis (5th ed.). Upper Saddle River, NJ: Prentice Hall.

Hu, F., Xie, D., \& Shen, S. (2013, August). On the application of the internet of things in the field of medical and health care. In Green Computing and Communications 
(GreenCom), 2013 IEEE and Internet of Things (iThings/CPSCom), IEEE International Conference on and IEEE Cyber, Physical and Social Computing (pp. 2053-2058). IEEE.

Islam, S. R., Kwak, D., Kabir, M. H., Hossain, M., \& Kwak, K. S. (2015). The internet of things for health care: a comprehensive survey. IEEE Access, 3, 678-708.

Jara, A. J., Belchi, F. J., Alcolea, A. F., Santa, J., Zamora-Izquierdo, M. A., \& Gómez-Skarmeta, A. F. (2010, March). A Pharmaceutical Intelligent Information System to detect allergies and Adverse Drugs Reactions based on internet of things. In Pervasive Computing and Communications Workshops (PERCOM Workshops), 2010 8th IEEE International Conference on (pp. 809-812). IEEE.

Lu, D., \& Liu, T. (2011, December). The application of IOT in medical system. In IT in Medicine and Education (ITME), 2011 International Symposium on (Vol. 1, pp. 272275). IEEE.

Pasluosta, C. F., Gassner, H., Winkler, J., Klucken, J., \& Eskofier, B. M. (2015). An Emerging Era in the Management of Parkinson's Disease: Wearable Technologies and the Internet of Things. IEEE J. Biomedical and Health Informatics, 19(6), 1873-1881.

Sheikh, N. J., \& Sheikh, O. (2016). Forecasting of biosensor technologies for emerging point of care and medical IoT applications using bibliometrics and patent analysis. Proceedings of the IEEE, 3082-3093.

Shin, D., \& Hwang, Y. (2017). Integrated acceptance and sustainability evaluation of Internet of Medical Things: A dual-level analysis. Internet Research, 27(5), 1227-1254.

Valera, A. J. J., Zamora, M. A., \& Skarmeta, A. F. (2010, January). An architecture based on internet of things to support mobility and security in medical environments. In Consumer Communications and Networking Conference (CCNC), 2010 7th IEEE (pp. 1-5). IEEE.

Wang, H., Yan, Y., Hu, Z., \& Zhang, Y. (2011). Consumer Acceptance of IOT Technologies in China: An Exploratory Study. In ICTE 2011 (pp. 2430-2435).

Wang, Y. W., Yu, H. L., \& Li, Y. (2011, April). Notice of retraction internet of things technology applied in medical information. In Consumer Electronics, Communications and Networks (CECNet), 2011 International Conference on (pp. 430-433). IEEE. 